\title{
Asymmetry of Institutional Talk in Post-Communist Poland. A Linguistic Approach
}

\author{
Mariusz Rutkowski \\ Uniwersytet Warmińsko-Mazurski w Olsztynie \\ Instytut Filologii Polskiej, Poland
}

Doi:10.5901/ajis.2013.v2n3p409

\begin{abstract}
Institutional talk can be defined as a type of communication situation taking place between an official and a client of an office in an institutional setting when the asymmetry of the relation is maintained. A critical discourse analysis will allow for discussing institutional talk in terms of power and domination. Symbolic power manifests itself in language and through language. Analyzing certain linguistic behaviours thus makes it possible not only to reveal the real intentions and aims, but also to reconstruct a social relation, with reference to the domination/submission criterion. Power and asymmetry are manifested in taking the floor, i.e. domination by speaking, controlling the topic, relations and roles in a conversation. The topic is controlled by linguistic means such as interrupting someone's utterance, using questions, or the right to control the code or variety of the language used. In order to control the relation one may use primarily addressative forms and means of persuasion of the 'inclusive we' type. The paper is a part of the author's linguistic research on institutional talk in Poland, performed on the basis of concrete material collected for this purpose in offices in Olsztyn (Poland).
\end{abstract}

1. Institutional talk ${ }^{1}$ has been defined in many different ways, and its range is limited in theoretical perspectives not only by spatial frames (eg. a dialog in an administrative office of a court, hospital or an authorities' office), but also by social and intradiscoursive frames. Understanding it by discourse limited by 'institutional context' is most obvious (Drew $\mathrm{i}$ Sorjonen 1997: 92), however this context does not have to mean the physical place of the dialog. After other scholars, (Drew i Heritage 1992), the interaction takes institutional form (becomes institutional) when the interlocutors have conversational goals aimed at work or a task: „an orientation by at least one of the participants to some core goal, task or identity [...] conventionally associated with institution" (1992: 22). Of a great importance are also the social conditions assuming particular roles takes place ritually by entering the area of an institution. The entrance itself becomes an act of social identification and taking a particular role. Entering an office of a court, hospital or any authorities' office one becomes (in the meaning of discursive role, but not only) a judge, a clerk, a doctor, a client or a patient. In principle, as far as the participants of an institution and institutional communication are concerned, two groups are distinguished - these are agents and clients (Ehlih i Rehbein 1994: 318). Agents in a way belong to an institution, they are bound by stable and permanent relations and carry out their institution's tasks, while clients are more casually acquainted with an institution, they are the subject of an institutions' actions and aims and their relations with an institution are more provisional. This differentiation has essential consequences for the description of institutional communication, particularly for the explanation of inequality of conversational roles which makes this communication asymmetrical. Although the roles of a client and an agent seem to be permanent ${ }^{2}$ and unchanging, it is said, especially in ethnometodological tradition, that these identities are constructed during the interaction: „Social reality is something that people construct together. When meeting each other on whatever stage people talk with each other, agree, argue and disagree. In other words, they negotiate social reality and construct interpretation of it" (Juhila, Poso, Parton, Hall 2008: 17). It can be assumed that being a member of one of those two interaction groups: a client or an agent, is permanent and unchanging, however the quality of this involvement is negotiated in a communication process every single time.

Here, institutional discourse will be understood as conversations between an institution's representatives and its clients, which concern an institution and take place in an institution's registered office. It meets Agar's point of view (1983), as he described institutional discourse as a relation between an institution and a client who needs institution's help in order to deal with their problem. In practice, it will be a description of conversations taking place in offices of many

\footnotetext{
1 This paper is a part of grant founded by Polish National Centre for Sciences (DEC 2011/03/B/HS2/04457).

2 Of course in the frame of institutional interaction; outside it, the roles are cancelled and any other roles can be applied as for instance a role of a father/grandfather, a neighbour or a member of religious community.
} 
kinds in Poland.

In such a communicational situation, mentioned above, an asymmetrical communication model is realized. This asymmetry is a result of the inequality in social roles: „Workplace interactions are frequently asymmetrical, that is there may be differences in the distribution of institutional power or expert knowledge between the participants" (Koester 2010:4). This inequality is not only socially sanctioned but it is also a source of not always conscious communicational inequality (asymmetry).

2. Apart from institutional context, outlined above, which establishes asymmetrical discourse, in the Polish administrative (official, office) discourse additional factors that increase the asymmetry of communication can be specified. These factors are of a socio-historical character and are based on a very special relation between the authorities and the society. These relations are the remains of certain social and political relations that developed over the centuries and shaped administrative, legal and regulatory structures of power. Firstly, what is worth attention is a big social stratification in the former Poland. Here the most important was differentiation of the noble class which included both magnates (aristocrats) and more numerous group called 'gentry'. The nobility constituted about $10 \%$ of all citizens, but had great privileges. For our deliberations, the most important is the fact that only the representatives of the nobility could take offices and exercise the power. The representatives of the most numerous social class - peasants - were completely deprived of any rights and their status can be compared to the one of slaves (publications). Such a social system and balance of power lasted for hundreds of years, basically until the partitions of Poland (late eighteenth century). To the majority of the society, from which the vast majority of today's Poles come from, then, the power was a domain of strangers.

The partitions were another very important factor that allows to understand the relations between the society and the government in the contemporary system. Having deprived Poles of their own state resulted in assuming administrative positions by the representatives of foreign countries or Poles cooperating with them. The power was thus in the hands of strangers, foreign enemies. This situation persisted over the next century, until 1918 when the Polish statehood was restored as a result of the Treaty of Versailles. Unfortunately, after the next 20 years another war, which ruined the country, broke out. The most severe were heavy casualties - Poland lost in total, depending on the sources, 16-22\% of the population, with the educated class having suffered greatest losses: officials, doctors, officers, teachers, priests and scientists. After World War II, it became necessary to supplement these losses. The new communist government willingly offered a kind of social advancement to the representatives of lowest layers: peasants and workers, mostly uneducated and deprived of basic cultural backgrounds. It was a deliberate action aimed at ensuring the obedient and loyal civil service the one hand, and on the other hand - antagonizing the society through a reversal of the traditional social order (it were the peasants who ruled over old masters). The period of communism is the third important historical factor that shaped the relations between the power and the society.

To sum up this part, let me emphasize one more time the socio-historical factors influencing the contemporary treatment of Poles by government representatives: 1 / the administrative authority has been for centuries a domain of minority (nobility), 2 / in the period of the Partitions the administrative authority was in the hands of the invaders: the Russians, Germans and Austrians and cooperating with them Poles 3 / under the communist rule the authority was synonymous with strange political system enforced by the Soviet regime. In all these systems, power was regarded by most people as an alien domain, a foreign domain, a domain of the others. It was especially noticeable in the era of PRL (the Polish People's Republic) when the juxtaposition of the government and the society is clearly visible on the basis of the dichotomy WE (ordinary citizens) vs. THEY (the government). This is evident in a number of feature or artistic texts, films and literature, and above all, in the general sense of ordinary people. For centuries, this dichotomy perpetuated in a variety of configurations, but never was power or state administration regarded by the citizens as their own ("ours"), but as the others' ("theirs"). This led to treating the state not as a community, the common good or common property, but as a foreign creation, external to the citizens. The average Pole does not identify with their state, but they treat it as a foreign power.

This common treatment of the state outlined above has a clear relation to how a citizen treats representatives of the state administration. After all, one has to contact the administration - it is necessary, in order to function in a society, to take certain administrative actions (pay taxes, make civil law transactions, to register marriage, birth or death, register a vehicle, build a house or receive a pension). Entering interaction with the authority representatives (whether government or local) an average Pole enters a relation with a "stranger". Unlike in other countries, where an official is treated as an advisor and a person who helps, a Pole sees an officer as a stranger, very often as a hostile who not only does not help but also piles up difficulties and disturbs. In a word - a Pole sees an official as a representative of an 
oppressive government. In relation with a government representative (eg. an official), a citizen is put in the role of supplicant who asks for a positive settlement of the case (it perpetuates in the characteristic patterns of official documents, such as application forms or request forms).

Despite the political changes after 1989 and the beginning of the democratization process, the old, formed throughout centuries power - society relation model lingers on. Without any doubts, it strengthens the asymmetric interaction between a citizen and an officer and substantially affects the quality of taking up linguistic behavior patterns (communication actions).

3. How is asymmetrical relation, established by the institutional context and reinforced by the historical and social factors, reflected in the aspect of administrative discourse - in fact in its fragment which is realized in communication of an official and a client? The first distinctive element is the use of symbolic power by the authorities, or even symptoms of symbolic violence, as P. Bourdieu stated - from monumental architecture to language.

The official language is the most important manifestation of symbolic violence, and at the same time it is the strongest element consolidating the asymmetry of communication. In an asymmetric arrangement it is an official who is the depositary (the owner) of knowledge and power, they are an expert, they also use specific phrases or vocabulary. This use of language is aimed at two things: first, it emphasizes the role of an officer as an expert, "the one who knows", and second, it downgrades the role of a citizen who is a layman and does not always understand specific official and often legal expressions. It is, therefore, inherently exclusive language, excluding language, one which reconstructs the asymmetry and increases the distance and social disproportion.

The most characteristic features of the Polish official language are: directivity, formality, impersonal nature of expression and the pursuit of precision (Wojtak 1993). All these features make all the texts that are created standardized, reproducing the pattern (see the chart) and mostly devoid of individual features. A receiver is reduced to a sub-contractor of an administrative decision, and the sender is an impersonal institution - who communicates with the citizen by grammatical forms making any close relations impossible. Most often these are verbs in third person singular ("he") eg. „Zarząd Spółdzielni Mieszkaniowej postanowił”, „Urząd Gminy ustalił wysokość opłat” 3 . This kind of announcements are a part of the symbolic violence - they inform about certain acts, decisions being a result of the action of the subjects, but in an impersonal way, so as to present a semblance of absolute necessity (this way they are objectified). These are the kind of "objective facts", taking place regardless of the sender, of their own will (which is obviously not true). When a citizen addresses an office in writing, they are required to write in the first person singular ("I" statements): „zwracam się z prośba", "oświadczam”, "informuje" 4 . So it is communication between an individual citizen and impersonal, collegial collective authority, which is another manifestation of the asymmetry of communication.

A very characteristic feature of the official language is the use of specialized expressions, words or phrases typical of the legal and administrative discourse. On the one hand this is understandable - the language of the documents carries legal validity and on the basis of these documents legal and administrative reality is constructed (decisions, judgments, justifications). The performative nature forces in a way another official language feature - the pursuit of precision (Wojtak 1993: 153). Precision is achieved when precise, often specialized language expressions are used. The fact that they are alien to an average user of language does not mean that the applicability in the discourse is impossible. It is just the opposite, for an official who is dominant in the situation such specialized and complex phrases are yet another means to emphasize the asymmetry. On the other hand, using simpler and more common expressions which would enable to explain a complex legal or administrative matter in more accessible way is, in written administrative discourse, unacceptable and would result in frivolous treatment of such a letter, and, in the process, an official.

It would seem that some of the symptoms of linguistic asymmetry outlined above can be reduced (cancelled or limited) in the spoken language in official talks. To some extent, this is correct. On the one hand, in the conversations some elements are reduced (more often instead of precise terms more colloquial equivalents are used), however, other conversational sings of asymmetry occur. These include: controlling the conversation, controlling the topic, asking questions, interruption or using pause (break). In these five behaviors an officer 's advantage is realized. It is widely known that the power of the conversation is closely connected with taking the floor: the one who speaks dominates, the one who listens - is subordinate (submissive). Therefore, the rules of giving the floor in a conversation, asking questions,

\footnotetext{
${ }^{3}$ An office (urzą) is masculine in Polish. In the free translation it is: "Board of Housing Cooperative decided on...", "Municipal Council has determined the fees."

4 "I ask you", "I therefore declare", "I inform" (literal translation)
} 
interrupting (eg, in order to clarify), which are in a large extent on an officer's side, are another means to an asymmetrical relation. It is clearly observable on the example of questions. The right to ask questions is a very vivid manifestation of symbolic power. It is conferred in a large extent to an official who in the course of conversation controls the subject of the conversation and at the same time extorts (according to the rules of conversation) responding to them by the customer. The control connected with asking questions is in a simple way due to the fact that the question is the first element of an adjacency pair. It is thus the first of two parts required in a conversation and lack of the other is thought, by interlocutors, to be significant (Sacks, Schegloff and Jefferson 1974). The distribution of power in asking questions is uneven in the relation an official- a client: an official usually asks questions, and the customer is required to answer them, while an official can ignore customer's possible questions.

As a result of all deliberations outlined above, in the everyday communication in official-client relation the asymmetry is not abrogated or weakened but it is even sanctioned and replayed. In the recent years, offices' actions aimed at moderation and equalization of the relation have been noticed. There has been a significant change in the forms of addressing: a citizen at an office is not longer called 'petent' (a supplicant), but 'klient' (a client) or 'interesant'(enquirer). Great changes have occurred in the spatial organization of the offices: a citizen does not have to stand in front of an official but now has available seating. Also physical barriers such as windows, massive desks, walls are removed. Officials, in turn, are often called 'client advisers', which, at least at the declarative aspect, locates them on the side of a citizen. These actions are the first step to break the centuries-old tradition of treating the state or an official, who represents it, like a stranger; and a citizen as a swindler and crook, who at all costs (even at the cost of fairness) wants to get the most favorable and profitable pricing arrangements and administrative decisions. It is therefore the first step towards equalization of the relations and forming a balanced and egalitarian system.

\section{References}

Agar, M. 1983. Institutional discourse, Text 5(3), 147-168.

Drew, P., Heritage, J. 1992. Analyzing talk at work: an introduction, in: Talk at Work, eds. P. Drew, J. Heritage, Cambridge: CUP, 3-65.

Drew, P., Sorjonen M.-L. 1997. Institutional Dialogue, in: Discourse Studies. A Multidisciplinary Introduction, ed. T.A. von Dijk, London: Sage, 92-118.

Ehlich K., Rehbein J., Institutionanalyse. Prolegomena zur Untersuchung von Kommunikation in Institutionen, w: G. Brunner, G. Graefen (red.), Texte und Diskurse, Oppladen, 287-350.

Juhila, K., Poso, T., Hall, C., Parton, N. 2003. Introduction: Beyond the Universal Client, in: K. Juhila, T. Poso, N. Parton 2003 (eds.). Constructing Clienthood in Social Work and Human Services : Interaction, Identities and Practices. London-New York: Jessica Kingsley Publishers, 11-25.

Koester, A. 2010. Workplace Discourse. London-New York: Continuum.

Sacks H., Schegloff E.A., Jefferson G. 1974. A simplest systematics for the organization of turn-taking for conversation, Language 50: 696-735.

Wojtak, M. 1993. Styl urzędowy, w: Współczesny język polski, red. J. Bartmiński, Wrocław: Ossolineum, 147-162. 